\title{
Ensino de línguas: passado, presente e futuro
}

Foreign language teaching: past, present, future

\section{Vilson Leffa \\ Universidade Católica de Pelotas/CNPq}

Resumo

O texto descreve as tendências históricas do ensino de línguas, envolvendo as mudanças no conceito de língua, na metodologia de ensino, no papel do professor e as relaçôes que se estabelecem entre esses três componentes. Em relação à língua, mostra o desenvolvimento de uma ênfase histórica no código, que posteriormente evolui para uma ênfase no sentido e chega à ideia de língua como ação. Em termos de metodologia, descreve a mudança que ocorreu entre o conceito de método, visto como solução universal, para o conceito de pós-método, com ênfase no contexto de aprendizagem. Finalmente, em relação ao professor, o texto mostra como seu papel tem mudado à medida que mudam os conceitos de língua e de método, passando da subordinação ao método para o exercício da autonomia.

\section{Palavras-chave}

Ensino de línguas, Objetivos de aprendizagem, Pós-método.

\section{Abstract}

This paper describes the historical trends of language teaching, involving changes in the concept of language, teaching methodology, teacher's role and the relationship between these 
three components. Considering language, this study shows the historical development of an emphasis on the linguistic code, which then evolves to an emphasis on meaning and ends up with an emphasis on language as action. In terms of methodology, it describes the move from the concept of method, seen as a universal solution, to the concept of post-method, with emphasis on the learning context. Finally, considering the teacher, the text shows that her/his role has changed, as concepts of language and method change, moving from subservience to method to the exercise of autonomy.

\section{Keywords}

Language teaching, Learning objectives, Post-method. 


\section{Introdução}

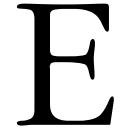

ste texto tem três objetivos assumidamente ambiciosos: o primeiro é fazer um breve retrospecto do ensino de línguas no tempo e no espaço, mostrando o domínio do método; o segundo é descrever o ensino de línguas na atualidade, caracterizado pela evolução do método ao pós-método; o terceiro objetivo, ainda mais ambicioso, é detectar as tendências que emergem dessa evolução. Entendo aqui como método um sistema de prescriçôes elaboradas para o professor, de cima para baixo, quer partindo do paradigma científico de uma determinada época (KUHN, 2005) ou da legislação vigente, incluindo os PCN (BRASIL, 1997) e as OCEM (BRASIL, 2006); entendo por pós-método um reconhecimento da capacidade de subversão do professor, que, com base na sua experiência e intuição, acaba invertendo a ordem estabelecida e faz na sala de aula aquilo que rigorosamente tem condiçôes de fazer; e finalmente vejo para o futuro uma mudança radical no papel do professor, que passa a trabalhar na invisibilidade.

Para atender a esses três objetivos, divido o texto em três partes. $\mathrm{Na}$ primeira parte, olho para o passado, caracterizado pela busca do método certo, o que paradoxalmente levou a uma proliferação desenfreada de diferentes métodos, cada um defendendo uma solução universal para o ensino de línguas, de modo que o mesmo método deveria funcionar para todos em todos os tempos e lugares - independentemente do professor que o aplicasse. Na segunda parte, olho para o presente, que se caracteriza pela inversão do que se pregava em relação ao método, que deixa de existir; agora é o professor e o contexto específico de aprendizagem que determinam o que acontece na sala de aula. Finalmente, na terceira parte, especulo sobre o futuro, principalmente em relação ao papel do professor, provavelmente ampliado pelo uso das tecnologias digitais.

Gostaria de fazer também duas ressalvas. A primeira é que não vejo os termos "segunda língua", "língua estrangeira", e "língua adicional" como sinônimos, mas, para evitar inúmeras repetições no texto, uso muitas vezes a sigla 
L2 como um termo abrangente para cobrir todas essas situaçōes. Acredito que o contexto de uso deixará claro para o leitor em que acepção a sigla está sendo usada. Para a língua materna uso a sigla L1. A segunda ressalva é que a troca entre primeira e terceira pessoa é feita deliberadamente. Em princípio, deixo na terceira pessoa o que vejo como consenso da área, ficando na primeira quando expresso algo que entendo como opinião adicionada ao texto. A ideia é conversar mais de perto com o leitor e, espero eu, tornar o texto mais agradável.

\section{Passado: o domínio do método e a submissão do professor}

A proposta de um método depende da percepção que o proponente tem de língua. Para alguns pesquisadores, por exemplo, língua é simplesmente um sistema independente composto de partes separadas umas das outras; nessa perspectiva cartesiana, para adquirir uma língua basta adquirir cada uma de suas partes. Nada poderia ser mais fácil: basta ao professor apropriar-se da língua, previamente desmontada pelos especialistas em seus elementos básicos, normalmente os itens lexicais e as regras sintáticas, e tentar inserir esses itens um a um na mente do aluno, na esperança de que, por um passe de mágica, ele reconstrua o sistema a partir desses elementos. Esse processo de inserção poderia ser ilustrado pela metáfora do artista de rua que monta a maquete de um navio dentro da garrafa, introduzindo as peças pelo gargalo; com a diferença de que o professor, ao contrário do artista, é apenas solicitado a inserir as peças na mente do aluno, deixando para ele a reconstrução do sistema.

Já quem vê língua, não como um sistema independente, mas como prática social, não consegue desmontá-la em elementos menores, porque a vê atrelada à comunidade que a usa; a língua, nessa perspectiva, não existe fora do evento comunicativo que a constitui. É como a cor que não pode ser percebida sem o objeto que a contém e a luz que a reflete; não podemos ver o azul se ele não estiver no céu, nas águas do mar ou mesmo numa folha de papel. Do mesmo modo, não podemos perceber a língua se ela não estiver sendo usada por alguém em algum tipo de interação com o outro. A língua é um objeto naturalmente complexo que reveste e é revestida por toda e qualquer prática social. Nessa concepção, o trabalho solicitado ao professor não é o de pôr a língua dentro do aluno (metáfora da garrafa), mas o de inserir o aluno na prática social. 
O ensino de línguas caracteriza-se também pela dualidade de sistemas linguísticos, envolvendo não só a língua a ser estudada mas também a L1 do aluno, que pode desempenhar um papel maior ou menor na aprendizagem da L2, dependendo do conceito que se tem de língua e de sua aprendizagem. Na longa caminhada dos métodos, houve momentos em que a L1 foi vista como um ponto de apoio a ser usado para a aprendizagem da L2; em outros momentos, como um empecilho que o aluno deveria evitar e esquecer, agindo como se ela não existisse.

O método, na sua essência, é um roteiro que se propõe para chegar a um objetivo. Na sua forma mais tradicional, pode ser resumido pelo uso da sigla SOPA (LEFFA, 2008a), assim constituída: (1) Seleção dos itens linguísticos a serem trabalhados pelo professor; (2) Ordenação dos itens, de acordo com algum critério pré-estabelecido (relevância, facilidade, etc.); (3) Prática dos itens selecionados para que sejam fixados pelos alunos; e (4) Avaliação da aprendizagem realizada pelos alunos.

Vejamos brevemente alguns desses roteiros que foram propostos ao professor, esclarecendo que a aprendizagem de línguas iniciou-se antes de seu ensino sistemático. Historicamente, tem-se um período que poderia ser chamado de pré-método, caracterizado pela ausência de qualquer método de ensino, que teve início com os sumérios por volta de 2.500 anos a.C. (TITONE, 1968) e parece ter se estendido até o início do cristianismo, depois de passar pelos egípcios e possivelmente pelos gregos, em que pese seu desprezo pelas línguas dos outros povos, vistos apenas como bárbaros (TITONE, 1968). A aprendizagem da língua acontecia pelo contato direto com os falantes nativos. Rigorosamente falando, o ensino da língua era algo desconhecido; no período do pré-método, havia apenas aprendizagem; uma aprendizagem sem um método que a sistematizasse.

Dificilmente qualquer outra área da educação terá criado tantos métodos de ensino como a área de línguas: historicamente temos dezenas, se não centenas de diferentes propostas de como a L2 deve ser ensinada, fruto provável da insatisfação gerada pelos diferentes métodos. O QUADRO 1 mostra uma lista dos mais conhecidos, por ordem cronológica e com as fontes básicas de referência (alguns sem tradução na língua portuguesa). Neste texto vamos abordar apenas o Método da Tradução, o Método Direto e a Abordagem Comunicativa, levando em consideração o impacto que tiveram no ensino de línguas, determinando o rumo de sua evolução e incluindo algumas questôes fundamentais como o lócus do sentido, a relação entre L1 e L2, a articulação entre sistema e função, o papel 
do professor, entre outras. Para um estudo mais detalhado das características de cada um, recomenda-se Leffa (1988).

\section{QUADRO 1}

Amostra de alguns métodos de ensino de línguas.

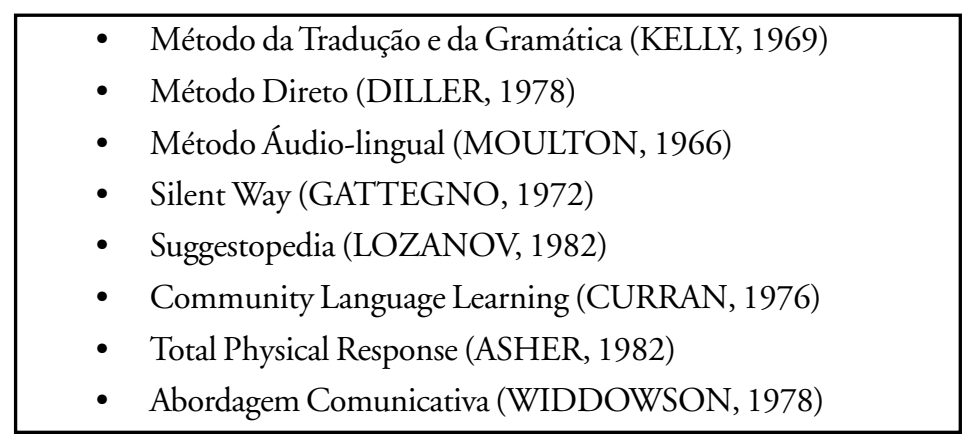

A necessidade do método surgiu quando se criaram as escolas, já na época do império romano, e se intensificou na Idade Média, quando o latim se tornou uma língua internacional, usada nas escolas, na igreja e nas universidades; para ensiná-la, usou-se com exclusividade quase absoluta, o método da tradução. Para compreender um texto, o aluno decorava listas de palavras da L2 e as associava às L1, aplicando também regras de sintaxe. Para produzir uma frase na L2, e invertendo o processo, a aplicação das regras de sintaxe assumia uma importância maior. Cobre-se aí um período de dois milênios, extremamente longo em número de anos, mas reduzido em termos de evolução, com muita estabilidade metodológica e pouca inovação. O QUADRO 2 resume as características do Método da Tradução. Os itens selecionados para o ensino eram o léxico e a sintaxe da L2; a ordem de apresentação era contextualizada, partindo da situação da sala de aula, com textos simplificados para exemplificar o emprego do léxico e das regras sintáticas, de modo dedutivo, e posteriormente de textos autênticos da literatura e cultura da L2; a prática consistia basicamente em exercícios de tradução e versão, mas perguntas de compreensão e interpretação dos textos selecionados também eram usadas; a avaliação era feita por meio de provas escritas. 


\section{QUADRO 2}

Características do Método da Tradução.

- Memorização do léxico

- Ensino de regras sintáticas

- Dedução

- Tradução de textos para a língua L1

- Versão de textos para a L2

- Ênfase na língua escrita

- Ênfase na literatura da L2

É interessante observar que "traduzir", na sua etimologia, significa conduzir de um lugar para outro, o que dá a ideia de que conhecer uma língua era trazer o significado para a L1, como se ele não pudesse existir na L2. A construção do sentido, tanto na produção de uma frase escrita ou falada como na sua compreensão durante a leitura ou a escuta, era feita indiretamente, sempre passando pela língua materna; daí também o uso da expressão "método indireto" como sinônimo de "método da tradução". Pode parecer estranho que se processasse a língua sempre em duas etapas, tanto na sua produção como na sua recepção, indo da expressão de uma língua para a expressão da outra, para daí então chegar ao significado, mas era assim que provavelmente acontecia; para que um falante de português, por exemplo, compreendesse uma palavra latina como "puella", ele teria antes que associá-la à imagem acústica da palavra portuguesa "menina” para então fazer a ponte com seu possível significado. Produzia-se, assim, o estranho efeito de falar em uma língua e pensar em outra. É claro que, com a prática, o processamento das duas etapas poderia acelerar-se, chegando a produzir a ilusão de uma etapa única, mas não a ponto de fundir língua e pensamento.

Quer pela distância do lugar de onde se olha, quer pela estabilidade histórica, os períodos iniciais da aprendizagem de línguas não são medidos em décadas ou séculos, mas em milênios: temos assim dois milênios para o pré-método e mais dois milênios para o método da tradução. É só no fim do Séc. 19 que a História inicia uma caminhada mais rápida, concentrando o tempo e o espaço.

O Método da Tradução e da Gramática, também conhecido como Método Indireto, gerou, ao longo de sua existência, fortes reaçôes contrárias, dando origem ao Método Direto, seu polo dialeticamente oposto, e mantido durante muito tempo em caráter recessivo, sem condiçôes de se manifestar. O Método 
Direto, em relação ao da Tradução, lembra de certo modo o negativo das fotos pré-digitais, não só por mostrar a foto ao contrário mas também por ser mantido tipicamente oculto no fundo escuro de alguma gaveta, ao contrário da foto que, depois de revelada a partir do negativo, era exposta na moldura. O Método Direto, durante muitos séculos, atuou na sombra do Método da Tradução e é sob esse aspecto que vamos resumi-lo aqui, tanto por oposição ao método dominante como pela força oculta que acaba se manifestando.

O caráter recessivo, não manifesto, do Método Direto pode ser demonstrado, por exemplo, no diálogo abaixo, transcrito de material usado nas escolas romanas do séc. 2 d.C., em tradução para o português:

O homem avança na direção do amigo e diz, abraçando-o, "Bom dia, Caius."

Este retribui a saudação e diz, "Prazer em te ver. Gostarias de vir conosco?" "Aonde?"

"Para ver nosso amigo Lucius. Vamos lhe fazer uma visita."

"O que aconteceu com ele?"

"Está doente."

"Desde quando?"

"Há alguns dias."

"Onde ele mora?"

"Não é longe daqui. Se quiseres podes ir conosco."

(YONEKURA, 1984, p. 20-21).

Há vários aspectos nesse exemplo que já demonstram alguns dos traços que séculos mais tarde caracterizariam o Método Direto, em oposição ao Método da Tradução. Em vez de ênfase na memorização do léxico e de regras sintáticas descontextualizadas, temos um diálogo situacional, que sugere ênfase no quotidiano; em vez da dedução, indo da regra para o exemplo, temos a indução, sugerida pelo uso do diálogo, que parte do exemplo para depois levar para a regra; em vez do texto literário, com exercícios de tradução, temos um texto que tenta caracterizar o dia-a-dia das pessoas, com mais probabilidade de ser recitado e dramatizado do que copiado e traduzido. O lócus do sentido passa da L1 para a L2, com o pressuposto de que o aluno deve ser capaz de aprender a pensar na L2. O uso da L1 deve ser evitado pelo aluno para que todo o tempo de estudo seja usado exclusivamente para a prática da L2 de modo que a língua se torne um hábito e flua naturalmente. 
Ao contrário do Método da Tradução, que sempre teve muitos detratores, o Método Direto caracteriza-se pelo grande número de defensores, incluindo nomes reconhecidos como Harold Palmer, Otto Jesperson e Emile de Sauzé (LEFFA, 1988). Na virada do séc. 19 para o séc. 20, este foi oficializado em vários países da Europa, tornando seu uso obrigatório nas escolas públicas. $\mathrm{Na}$ segunda metade do séc. 19, ele deu origem ao Método Áudio-lingual nos Estados Unidos, depois divulgado para o resto do mundo, com base em nomes importantes como Bloomfield, na área da Linguística, Skinner na Psicologia e Fries e Lado, na área da Linguística Aplicada.

Depois do Método da Tradução e do Método Direto, o maior impacto no ensino de línguas veio do que se convencionou chamar de Abordagem Comunicativa, no final da década de 1970. Descobriu-se que as pessoas aprendiam línguas não para pronunciarem frases sintaticamente corretas e sem sotaque, mas para alcançar objetivos práticos, visando determinados resultados, como entender um manual de instruçôes, interagir adequadamente com um cliente ou obter informaçôes sobre um produto. O léxico e a sintaxe de uma língua não existiam apenas para expressar noções de tempo e espaço, representando a realidade que nos cerca, mas também para transformar essa realidade. Uma simples frase como "Estou cansado" pode ser dita não apenas para revelar cansaço mas também para justificar um erro cometido, rejeitar um convite para jantar fora ou informar a alguém que se quer retirar da festa e voltar para casa.

O lócus do sentido não está nem na L1 nem na L2, mas no efeito que ele produz no interlocutor, e a L1, dependendo do contexto, pode ser livremente usada na sala de aula. Usamos a língua não apenas para relacionar a expressão ao seu conteúdo, espelhando a realidade, mas para agir sobre a realidade. A evolução que se observa do Método da Tradução para o Método Direto e daí para a Abordagem Comunicativa passa de uma ênfase no código para uma ênfase no significado até chegar a uma ênfase na ação: falar é fazer.

\section{Presente: o domínio do pós-método e a insurreição do professor}

Não faltam críticas à ideia de método como roteiro para chegar a um objetivo. Uma das mais contundentes é de Matusov, que jocosamente apresenta o seguinte exemplo: 
William Shakespeare sentou-se à escrivaninha, pegou a pena, mergulhou-a no tinteiro, e escreveu: "Objetivo de Desempenho: até o final desta peça, o público irá experimentar a catarse de um amor sem fronteiras, derramar lágrimas sobre a morte de jovens amantes, e sentir vergonha das brigas de família sem sentido. Padrões de desempenho, de acordo com as normas do Reino da Inglaterra: promoção da catarse: 3,2; apreciação do sentimento amoroso: 4,7; e crítica do comportamento antissocial 2,1". Foi assim que Shakespeare começou sua famosa obra Romeu e Julieta (MATUSOV, 2011, p. 21).

Para Matusov, querer alcançar a aprendizagem é como querer alcançar o nirvana, a felicidade, o amor: quanto mais a pessoa se empenha em consegui-los, mais distante eles ficam. A aprendizagem, o nirvana, a felicidade e o amor não são atividades orientadas a objetivos e, por isso, não podem ser planejadas. Para ele, o que existe são apenas açôes que, incidentalmente, podem levar à aprendizagem, que passa a ser vista não como objetivo da ação do professor, mas como um possível subproduto; não cabe ao professor planejar e ensinar, mas provocar o aluno em três instâncias: provocar discordando do aluno, provocar apresentando paradoxos e provocar lançando problemas. É semelhante ao que propõe Vetromille-Castro (2007, p. 211) com o conceito de professor perturbador, visto como aquele que propõe desafios e causa instabilidades, levando o aluno à atuação autônoma, e não apenas ao simples fornecimento de respostas. "Ensinar não é uma questão de métodos e técnicas, mas de personalidade; influência duradoura é radiação pessoal..." Josef Albers, 9 de janeiro de 1940 (apud MATUSOV, 2011, p. 21).

Suprindo o espaço vazio, deixado pela abolição do método, Kumaravadivelu (2001) cunhou o termo "pós-método", para tentar descrever o que está acontecendo no ensino de línguas, que, ao contrário do método, não foi abolido. Não só continua existindo como também foi modificado, sofrendo influências da contemporaneidade, calcada na ideia de "pós-" (pós-modernismo, pósestruturalismo, e até pós-humanismo, para citar apenas três exemplos), aumentando a necessidade de explicá-lo e compreendê-lo: a verdade é que as pessoas continuam estudando línguas e os professores continuam tentando ensiná-las. O uso do pós hifenizado ("pós-”) mostra que as ideias perpassam diferentes disciplinas, e que o ensino de línguas não está imune ao que acontece em outras áreas. Pela sua relevância no ensino e aprendizagem de línguas, vamos 
resumir o que caracteriza o pós-método, com base nas ideias de Kumaravadivelu (2001, 2003, 2006a, 2006b).

O ensino de línguas não deve acontecer em um mundo abstrato, meramente teórico e construído por autoridades, seja no sentido autoritário, com base no poder, seja no sentido autorizado, como base no saber, mas deve estar situado em um determinado contexto, com base na realidade, garantindo ao professor a opção de agir dentro daquilo que é plausível em seu contexto (PRABHU, 1990). "Qualquer pedagogia com base no pós-método tem que ser construída pelo próprio professor, levando em consideração particularidades políticas, culturais, sociais e linguísticas" (KUMARAVADIVELU, 2006b, p.69). Há uma ênfase na ideia de mudança, cujo objetivo principal não é descrever o mundo como ele é, mas como ele deveria ser. Kumaravadivelu (1994) desdobra sua proposta em dez macroestratégias, que podem ser assim resumidas:

(1) maximizar as oportunidades de aprendizagem, tratando a sala de aula como uma prática social conjunta entre professor e alunos;

(2) facilitar ao aluno interação negociada com o professor e com os colegas para acelerar a compreensão e construção de sentido, usando, por exemplo, atividades em grupo;

(3) minimizar os desencontros perceptuais entre as intenções do professor e as interpretações do aluno;

(4) ativar a heurística intuitiva dos alunos, fornecendo input linguístico suficiente para que eles possam chegar às regras da língua pela autodescoberta;

(5) incentivar a consciência linguística do aluno, não com base nas regras tradicionais da gramática, mas por meio de atividades que evidenciem também a importância da língua em seus aspectos formais;

(6) contextualizar o input linguístico, usando tarefas de solução de problemas, simulações, RPG, e outras atividades que integram vários componentes linguísticos;

(7) integrar as habilidades linguísticas, incluindo a escuta, a fala, a leitura e a escrita;

(8) promover a autonomia do aluno, dando-lhe o conhecimento necessário para gerenciar sua própria aprendizagem;

(9) aumentar a consciência cultural dos alunos, propiciando contato com 
diferentes culturas, incluindo a cultura da língua materna;

(10) assegurar relevância social, partindo do contexto do aluno.

É possível perceber duas ideias seminais nessas dez macroestratégias que seriam desenvolvidas mais tarde pelo autor (KUMARAVADIVELU, 2006b). A primeira ideia já está até indicada no subtítulo do artigo, pelo jogo de sentido que o autor faz com o uso de parênteses na palavra "(e)merging" - "(E)merging strategies for second / foreign language teaching" -, sugerindo a integração que deve emergir das diferentes atividades; a segunda, na escolha de palavras como "consciência", "interação negociada" e "autonomia", sugerindo uma ênfase no aluno como sujeito de sua aprendizagem, capaz de negociar e dialogar com professores e colegas. Vejamos como essas duas ideias contribuem para caracterizar o ensino de línguas na contemporaneidade, partindo das ideias apresentadas por Kumaravadivelu, mas incorporando também outros autores.

"Merging" dá a ideia de que todas as nossas açôes são atravessadas pelas açôes dos outros. A aprendizagem de uma língua não se restringe ao domínio do código, mas estende-se ao contexto em que vive o aluno, estabelecendo relaçôes com outras disciplinas da escola, com os interesses da comunidade e suas necessidades, com a cidadania, enfim. Não se exclui a cultura do outro, mas também não se exclui a própria cultura. Integra-se, fazendo o "merging".

A pedagogia de projetos é um dos exemplos que podem ser apresentados de como implementar essa integração (HERNÁNDEZ, 1998; MACHADO, 2000; ALMEIDA, 2002; PRADO 2009). De acordo com Prado (2009, p. 4):

A pedagogia de projetos, embora constitua um novo desafio para o professor, pode viabilizar ao aluno um modo de aprender baseado na INTEGRAÇÃO entre conteúdos das várias áreas do conhecimento, bem como entre diversas mídias (computador, televisão, livros) disponíveis no contexto da escola. (Ênfase no original.).

Para um exemplo de como a pedagogia de projetos pode ser usada no ensino de línguas, recomendamos Schlatter e Garcez (2012). O uso de algumas propostas baseadas nos recursos da internet, como a da Webquest (ABAR; BARBOSA, 2008), também poderia ser citado, na medida que prioriza o trabalho em grupo, privilegia a integração de diferentes áreas de conhecimento, apoia-se no uso de diferentes mídias e parece ter apelo motivacional significativo para os jovens (SANTOS, 2012). 
A essência da pedagogia de projetos, já está contemplada nos PCN quando apresenta os temas transversais para abordar "questōes sociais consideradas relevantes (...) de abrangência nacional e até mesmo de caráter universal" (BRASIL, 1997, p. 64). Esses temas, que são de interesse específico de uma determinada comunidade, podem ser definidos no âmbito do estado, da cidade ou da escola. A possibilidade de ser definido no âmbito da escola abre um espaço para a intervenção do professor, ainda que em nosso país muitas dessas intervenções tenham tido origem na ação do estado, por meio de leis, decretos, estabelecimento de parâmetros e até de orientações curriculares com sugestão de atividades para o professor fazer na sala de aula (Vejam-se, por exemplo: BRASIL, 1997; BRASIL, 2006; SCHLATTER; GARCEZ, 2009).

Na busca de um mundo como ele deveria ser, a emancipação do professor, que guia sua ação não pelo que os teóricos dizem que ele deve fazer, mas por sua própria reflexão e pesquisa (SCHÖN, 1995; TRIP, 2005; THIOLLENT, 2005; LEFFA, 2008b), a autonomia do aluno parece ter mais possibilidade de emergir, com base até no exemplo dado pelo professor, que ao adquirir voz habilita-se também a dar voz ao aluno. A facilidade de acesso à informação, a disponibilidade de uma plateia global, sem restriçōes de fronteiras geográficas, a emergência de fenômenos como a Web 2.0 e as redes sociais que cobrem o planeta são todos fatores que podem contribuir para tornar o aluno agente de sua própria aprendizagem; deixa de ser apenas o depositário da informação na visão da educação bancária criticada por Paulo Freire (FREIRE, 1983), já há tanto tempo superada, mas que ainda tende a persistir.

Sobre a questão da pedagogia crítica, com base em Freire, e apresentada por Kumaravadivelu (2006b) como uma das direçōes do ensino de línguas na contemporaneidade, seria relevante acrescentar também a perspectiva bakhtiniana, com ênfase na pedagogia dialógica (MATUSOV, 2009), que não contraria, mas consolida e refina as propostas de Freire. Para Matusov, a pedagogia dialógica não é uma opção; a pedagogia é sempre dialógica, quer os participantes ou observadores a percebam ou não desse modo; onde não há diálogo, não há construção de sentido, que é sempre instaurado de modo imprevisível entre o locutor e o interlocutor. A aprendizagem é sempre uma surpresa tanto para o professor como para o aluno e, por isso, não pode ser planejada. "O diálogo é impossível se um dos participantes sabe de antemão como ele termina. Na melhor das hipóteses, seria uma manipulação artificiosa 
de quem sabe mais em direção a uma conclusão já conhecida; na pior, uma imposição violenta do conhecimento, habilidade e atitude do professor sobre o aluno (MATUSOV, 2009, p. 3).

O ensino de línguas no presente caracteriza-se, assim, por três grandes linhas de ação. A primeira é a substituição da abordagem comunicativa, como proposta unificada de ensino, por uma série de estratégias diversificadas que buscam atender as condiçôes de aprendizagem do aluno, a realidade do professor e o contexto em que tudo isso ocorre, variando sempre de um lugar para outro. A segunda linha de ação diz respeito à integração da aprendizagem das línguas com o seu entorno, levando em consideração a realidade social do aluno; com a proposta prática de que a melhor maneira de integrar o aluno ao seu meio, desenvolvendo a cidadania, é pela implantação da pedagogia de projetos. Finalmente, a pedagogia dialógica permite ao professor construir com o aluno o conhecimento linguístico que historicamente valoriza o próprio contexto em que vivem.

A diversidade de estratégias, pelas opções que oferece ao professor, a pedagogia de projetos, pela ênfase no contexto específico de sua ação e a pedagogia dialógica, pela possibilidade que oferece da construção mútua do saber entre os sujeitos diretamente envolvidos na aprendizagem implicam uma mudança radical na direção do ensino e aprendizagem de línguas. A visão de uma teoria unificada, imposta de cima para baixo para ser aplicada aos mais diferentes contextos, como acontecia no longo período histórico do método, é agora substituída por uma prática diversificada, enraizada na realidade do dia-a-dia de cada um. Duas comunidades diferentes, estudando a mesma L2 podem estar aprendendo duas L2s diferentes; um aluno francês, aprendendo inglês, por exemplo, aprende um inglês diferente do aluno brasileiro. A opção por diferentes estratégias, a integração com o contexto e a possibilidade do diálogo ampliam a ação do professor, dando-lhe um papel que nunca teve antes. Se durante muito tempo buscou-se um método à prova de professor, agora busca-se um professor à prova de um método. Tudo aponta para sua autonomia. Mesmo a intervenção maciça de nosso país no ensino, inclusive de línguas (BRASIL, 2011), em aparente consonância com uma preocupação global com a educação (COPE; KALANTZIS, 2009) não é feita, a meu ver, para tolher o trabalho do professor, mas para emancipá-lo e até insurgi-lo. 


\section{Futuro: o domínio da emergência e a invisibilidade do professor}

Quando ensinamos uma língua podemos recorrer à memória e usar o que já sabemos; podemos recorrer ao nosso entorno e usar os recursos de que dispomos, mas principalmente devemos olhar para o futuro e tentar prever as circunstâncias de uso da língua pelos alunos. Não se ensina para o passado nem para o presente, mas para uma possibilidade de uso mais adiante. Essa necessidade de olhar para o futuro traz o problema da dificuldade crescente de prevê-lo, considerando que a História caminha cada vez mais rápido, acelerando as mudanças, e o futuro torna-se cada vez mais imprevisível. Na Antiguidade, o pai ensinava seu ofício ao filho, esse ao neto e, assim, sucessivamente, geração após geração, num mundo que, por permanecer praticamente o mesmo durante séculos, era tão linearmente previsível que nem havia a necessidade de prevê-lo (LEFFA, 2003): a História era um caminho de mão única e sem desvios. Hoje, no entanto, embaraçamo-nos em bifurcaçôes complexas que se multiplicam em inúmeras direções e tornam a previsão do futuro muito mais difícil, pela infinidade de caminhos que se abrem pela frente. $O$ presente é um labirinto que nos impóe a necessidade de achar logo a saída sem, no entanto, oferecer pistas do que podemos encontrar depois da primeira curva, deixando-nos diante de um enigma sem solução: quanto maior a necessidade de prever o futuro, mais imprevisível ele se torna.

É dessa imprevisibilidade que surge a ideia de emergência, trazendo uma complexidade que não pode ser prevista a partir dos elementos que conhecemos da condição precedente (EMMECHE et al., 1997, p. 85). Tudo é ampliado, multiplicado, complexificado, tanto para o corpo como para a mente. Em relação ao corpo, somos obrigados à automatização rápida do gesto, que logo evolui para outro gesto, incorporando objetos a partes de nosso corpo e formando um órgão funcional (KAPTELININ, 1996) que está em constante mudança. A partir do livro impresso, no qual as páginas eram viradas diretamente pelos dedos, quem iria prever o mecanismo de mediação do mouse para avançar na leitura da tela? A partir do mouse, quem iria prever a volta ao dedo na leitura da tela multitoque do tablet, não só para mudar de página diretamente, sem mediação, mas também para ampliar ou reduzir graficamente o texto? A partir do toque na tela, quem iria prever o uso do gesto solto no ar para controlar o computador, como começa a acontecer com o Kinect (MICROSOFT, 2010) e o Leap Motion (DÊ ADEUS, 
2012)? Quem iria prever, a partir do teclado físico, que um dia ele ficaria escondido dentro da tela, aparecendo apenas quando necessário? Quem iria prever que seríamos intimados a uma readaptação constante no nível do domínio automatizado do gesto, em que não se permite a reflexão e a espera? Em relação à mente, quem iria prever a inesperada necessidade de convivência cognitiva com os objetos que surgem ao nosso redor, e que nos levam a pensar de modo diferente, porque nossa mente se estende sobre eles (CLARK, 1997)? Há uma década, quem iria prever a facilidade de acesso à informação propiciada pelos motores de busca na internet? Quem iria prever que passaríamos tão rápido da reflexão para a refração, entendendo por reflexão o retorno do indivíduo sobre si mesmo, a semelhança de uma imagem no espelho, e por refração, o retorno de múltiplas imagens de múltiplos indivíduos, que se desdobram a nossa frente em um número infinito de combinações, como um calidoscópio. No domínio da emergência, nada é permanente a não ser a mudança.

Falar do futuro é navegar na incerteza. O que segue, portanto, é de natureza especulativa e baseia-se no pressuposto de que só é possível prever o futuro quando se olha para o passado. Proponho que estamos no caminho da invisibilidade, levados pelo desejo de ver menos e fazer mais, paradoxalmente acarretando um aumento da influência do professor e da autonomia do aluno.

Em relação ao ensino, uma possível tendência histórica que se observa quando se olha para o caminho percorrido, é a gradual perda da visibilidade do professor. Antes ocupava um estrado na frente dos alunos em posição superior; depois desceu do estrado, mas permaneceu ainda destacado na frente de todos; mais tarde saiu da posição de destaque e misturou-se com os alunos; com o tempo dividiu suas tarefas pedagógicas com objetos e recursos de aprendizagem, incluindo material impresso, laboratórios de línguas e computadores; atualmente tem trabalhado também a distância, mediado por tecnologias e alunos monitores. No início o professor era o centro da aula, depois foi para a margem, mais tarde ficou distante e minha previsão é de que futuramente desaparecerá na invisibilidade.

É necessário que se intercalem aqui algumas considerações do mundo físico em que vivemos sobre a questão da invisibilidade. Algo pode tornar-se invisível de inúmeras maneiras, e há pelo menos três que devem ser destacadas aqui: transparência, camuflagem e ocultação. Algo pode ser invisível quando é transparente, como o ar que nos cerca ou o vidro de uma porta, que, quando 
limpo, nos permite ver com clareza o que está do outro lado. Na natureza, a mãe d'água, é um peixe que pela sua transparência fica invisível dentro do mar. Outra maneira de instanciar a invisibilidade é pela camuflagem, quando um objeto, animal ou pessoa fica totalmente integrado ao ambiente. É o caso, por exemplo, do camaleão, que muda de cor, conforme o fundo sobre o qual se encontra ou de uma pessoa que se maquia para ficar parecida com as outras ao seu redor, tão integrada na multidão que passa despercebida. Um terceiro tipo de invisibilidade acontece quando uma coisa está oculta atrás de outra: a pele atrás das roupas, as joias dentro de um cofre, o motor de um automóvel sob o capô e tantas outras coisas das quais às vezes nem suspeitamos: o mercúrio no morango que comemos, o vírus no programa de computador que usamos, o indeferimento do burocrata sobre o documento que entregamos na repartição. $\mathrm{Na}$ área da educação, podemos argumentar que o professor, ao usar a transparência, deixa de se interpor entre o aluno e o conteúdo; pela camuflagem, disfarça sua presença, misturando-se ao conteúdo; e pela ocultação, põe o conteúdo na frente do aluno, ficando ele, o professor, não no meio, mas do outro lado. A invisibilidade do professor deixará o conteúdo mais visível para o aluno.

A invisibilidade envolve também questôes de poder, autonomia e o desejo de não ver. Em termos de poder, a relação tem sido vista geralmente do lado negativo, na medida que somos vigiados e punidos pelo que não vemos, como no exemplo do Panopticon de Foucault (1977). Não discordo de Foucault, mas defendo a ideia de que o poder exercido na invisibilidade pode nos afetar não só de modo negativo mas também positivo. Não é necessário ser um Pangloss, o personagem ingenuamente otimista de Voltaire (1931), para aceitar que, às vezes, podemos ser também beneficiados por algo que não vemos.

Para o professor, a perda gradual de sua visibilidade, descendo do estrado e sumindo pelas margens, não significa perda de poder. Pelo contrário, quanto mais longe dos olhos do aluno ficar o professor, maior poderá ser sua ação sobre ele, desde que seja capaz de se preparar para ocupar os espaços que se abrem entre ele e o aluno, abrangendo áreas cada vez maiores. Para atuar adequadamente sobre esses espaços, surge a necessidade de investir mais no planejamento, preparação e avaliação do conteúdo a ser distribuído aos alunos, sem cair na tentação de transformar o ensino em uma linha de montagem da era fordiana, oferecendo a todos o mesmo produto. A distância mediada pelos recursos humanos e pela infraestrutura ampla deve, ao mesmo tempo, dificultar a padronização do ensino e facilitar a construção conjunta do saber. 
É possível argumentar que, quando vemos muito, aprendemos pouco, como no conhecido problema de Orwell, proposto por Chomsky e seus seguidores, segundo o qual, do ponto de vista político, somos expostos a muita informação e aprendemos muito pouco. É como se a riqueza de estímulo do meio-ambiente, o excesso de visibilidade, levasse à indiferença e à apatia, gerando a alienação política. Por outro lado, a pobreza de estimulo linguístico do meioambiente, ainda dentro da perspectiva chomskyana, não impede que a pessoa adquira a língua materna. Parece que justamente aprende mais porque vê menos; as regras linguísticas que o falante desenvolve são, na realidade, imperceptíveis no meio ambiente, não tendo aquela visibilidade extrema dos dados políticos disseminados por todos os meios de comunicação de massa. Temos na aquisição da língua, a versão chomskyana do problema de Platão, ou seja, como é que expostos a tão pouco aprendemos tanto, diferentemente da política, a qual somos expostos a tanto e aprendemos táo pouco? Defendo aqui a ideia de que quando vemos menos, desejamos mais. A visibilidade mata a desejo.

Quando se tem um foco, o meio que se usa para alcançá-lo torna-se invisível. $\mathrm{O}$ astrônomo quando procura uma estrela não vê o telescópio que a aproxima, mas a estrela, do mesmo modo que o biólogo não vê o microscópio, mas a célula ampliada pelo instrumento, como também o neurologista não vê o tomógrafo, mas o detalhe do cérebro que estava oculto dentro do crânio e que foi desvelado pelo aparelho. Todos esses processos de visibilização trazidos pela ciência, aproximando, ampliando ou desvelando o objeto de estudo, possuem uma universalidade que provavelmente um dia se refletirá no ensino de línguas e tornará o professor invisível. O futuro é o sumiço do professor: quer, no mínimo, pela transparência, permitindo que o aluno veja o objeto de estudo do outro lado, quer, idealmente, como instrumento invisível que aproxima, amplia ou desvela o objeto a ser aprendido pelo aluno. Quanto mais visível for o professor, mais atrapalhará a aprendizagem do aluno, que não deve olhar para o professor, mas para o conteúdo que deseja aprender; precisará do professor ao seu lado não a sua frente, do mesmo modo que o jogador precisa do técnico à margem do campo; o técnico que se colocar entre o jogador e a bola apenas atrapalhará o jogo. Séculos de História mostraram que o professor não pode aprender pelo aluno, que precisa exercer a autonomia, inclusive do desejo. Aprender e desejar pelo outro leva ao antagonismo, sem possibilidade de diálogo, gerando a violência que tem marcado a sala de aula do passado e do presente. Para o futuro, vejo na invisibilidade do professor feito instrumento a possibilidade de trabalhar com o aluno; não contra ele. 


\section{Conclusão}

Este artigo é uma tentativa de investigar a direção em que caminha o ensino de línguas. Para isso, lança-se um olhar sobre seu passado, buscando nesse olhar entender o presente e vislumbrar o futuro. A evolução do papel do professor no contexto em que atua foi o ponto de referência que orientou o desenvolvimento do texto e sua perspectiva.

No passado, percebe-se que o professor estava subordinado ao método, visto como a solução para o ensino de línguas. A busca incessante de um método certo, de aplicação universal e que superasse as deficiências do professor, deu origem a inúmeras propostas, todas elas, no entanto, com resultados que sempre deixaram a desejar. O longo período histórico de domínio do método pode ser descrito como um período de muitas mudanças e pouca evolução, caracterizado por constantes avanços e recuos. O que se afirmava num determinado momento era negado no momento seguinte, incluindo conceitos fundamentais como o de língua e aprendizagem, levando a um esgotamento metodológico. O sonho de um método único e infalível tinha acabado.

No presente, depois de se chegar à constatação histórica de que o método produzia mais sequelas do que soluçôes, a desilusão foi tão grande que se optou drasticamente pela sua extinção; o ensino de línguas tinha chegado à era pósmétodo. Chegava-se à conclusão que cabia ao professor decidir o que fazer na sua sala de aula, partindo de seu contexto de atuação, considerando a realidade dos alunos e a relação com outras áreas de conhecimento. Para fazer a integração com o entorno cria-se a pedagogia de projetos e tenta-se desenvolver a aprendizagem crítica e esclarecida da L2.

Finalmente, para o futuro, especulo que o professor trabalhará na invisibilidade, para tornar o conhecimento mais visível para o aluno, posicionando-se ao seu lado, na sua retaguarda, ou do outro lado do conteúdo, mas sempre deixando desobstruído o espaço que fica entre o aluno e o conhecimento. Quanto mais invisível for a atuação do professor perante o aluno, mais visível será o objetivo da aprendizagem. 


\section{Referências}

ABAR, C. A. A. P.; BARBOSA, L. M. Webquest um desafio para o professor: uma solução inteligente para o uso da internet. São Paulo: Avercamp, 2008.

ALMEIDA, M. E. B. de. Educação, projetos, tecnologia e conhecimento. São Paulo: PROEM, 2002.

ASHER, J. Learning another language through actions: the complete teacher's guidebook. 2. ed. Los Gatos, CA: Sky Oaks Productions, 1982.

BRASIL. Parâmetros Curriculares Nacionais: apresentação dos Temas Transversais. Secretaria de Educação Fundamental, Brasília, MEC/SEF, 1997.

BRASIL. Orientaçôes Curriculares para o Ensino Médio: linguagens, códigos e suas tecnologias. Brasília: Ministério da Educação, Secretaria de Educação Básica, 2006. v. 1. p. $85-124$.

BRASIL. Guia de livros didáticos: PNLD 2012: Língua Estrangeira Moderna. Brasília: Ministério da Educação, Secretaria de Educação Básica, 2011.

CLARK, A. Being there: putting brain, body and world together again, Cambridge: MIT Press, 1997.

COPE, B.; KALANTZIS, M. Multiliteracies: new literacies, new learning. Pedagogies: An International Journal, v.4, n. 1, p.164-195, 2009.

CURRAN, C.A. Counseling-learning in second language. East Dubuque, IL: Counseling-Learning Publications, 1976.

DÊ ADEUS ao mouse. Zero Hora, Porto Alegre, 30 de maio, 2012. ZH Digital, p. 1.

DILLER, K. C. The language teaching controversy. Rowley, MA: Newbury House, 1978.

EMMECHE, C.; KOPPE, S.; STJERNFELT, F. Explaining emergence: towards an ontology of levels. Journal for General Philosophy of Science, v. 28, n. 1, p. 83-119, 1997.

FOUCAULT, M. Vigiar e Punir: nascimento da prisão. Petrópolis, Vozes, 1977.

FREIRE. P. Pedagogia do Oprimido. 13. ed. Rio de Janeiro: Paz e Terra, 1983.

GATTEGNO, C. Teaching foreign languages in schools: the silent way. 2. ed. New York: Educational Solutions, 1972.

HERNÁNDEZ, F. Transgressão e mudança na educação: os projetos de trabalho. Porto Alegre: ArtMed, 1998. 
KAPTELININ, V. Computer-mediated activity: functional organs in social and developmental contexts. In NARDI, B. (Org.). Context and consciousness: Activity Theory and human-computer interaction. Cambridge, Massachusetts: MIT Press, 1996. p. 45-68.

KELLY, L. G. 25 centuries of language teaching. Rowley, Mas.: Newbury, 1969.

KUHN, T. S. A estrutura das revoluções científicas. Trad. Beatriz V. Boeira e Nelson Boeira. São Paulo: Editora Perspectiva, 2005.

KUMARAVADIVELU, B. The postmethod condition: (E)merging strategies for second/foreign language teaching. TESOL Quarterly, v. 28, n. 1, p. 27-48, 1994.

KUMARAVADIVELU, B. Toward a postmethod pedagogy. TESOL Quartely, v. 35, n. 4, p. 537-60, 2001.

KUMARAVADIVELU, B. Beyond methods: macrostrategies for language teaching. New Haven: Yale University Press, 2003.

KUMARAVADIVELU, B. Understanding language teaching: from method to postmethod. Londres: Lawrence Erlbaum Associates, 2006a.

KUMARAVADIVELU, B. TESOL methods: changing tracks, challenging trends. TESOL Quarterly, v. 40, n. 1, p. 59-81, 2006 b.

LEFFA, V. J. O ensino do inglês no futuro: da dicotomia para a convergência. In: STEVENS, C. M. T.; CUNHA, M. C. (Org.). Caminhos e colheita: ensino e pesquisa na área de inglês no Brasil. Brasília: Editora UnB, 2003. p. 225-250.

LEFFA, V. J. Como produzir materiais para o ensino de línguas. In: LEFFA, V. J. (Org.). Produção de materiais de ensino: prática e teoria. 2. ed. Pelotas: Educat, 2008a. p. 15-41.

LEFFA, Vilson J. Malhação na sala de aula: o uso do exercício no ensino de línguas. Revista Brasileira de Linguistica Aplicada, v. 8, n. 1, p. 139-158, 2008 b.

LEFFA, V. Metodologia do ensino de línguas In: BOHN H. I; VANDRESEN, P. Tópicos em linguística aplicada: o ensino de línguas estrangeiras. Florianópolis: UFSC, 1988. p. 211-236.

LOZANOV, G. Suggestology and suggestopedia. In BLAIR, R.E. (Ed.), Innovative approaches to language teaching. Rowley, MA: Newbury House, 1982, p. 146-159.

MACHADO, N. J. Educação: projetos e valores. São Paulo: Escrituras Editora, 2000.

MATUSOV, E. Journey into dialogic pedagogy. New York: Nova Science Publishers, 2009. 
MATUSOV, E. Authorial teaching and learning. In: WHITE, E. J.; PETERS, M. (Org.). Bakhtinian Pedagogy: opportunities and challenges for research, policy and practice for education across the globe. New York: Peter Lang, 2011. p. 21-46.

MICROSOFT to launch Xbox Kinect in November. The Economic Times, 16 ago. 2010. Disponível em: <http://articles.economictimes.indiatimes.com/2010-08-16/ news/27569063_1_gaming-market-ps2-gaming-consoles>. Acesso em: 30 maio 2012. MOULTON, W. G. A Linguistic guide to language learning. New York: Modern Language Association of America, 1966.

PRABHU, N. S. There is no best method-why? TESOL Quarterly, v. 24, n. 1, p. 161-176, 1990.

PRADO, M. E. B. B. Pedagogia de projetos. Gestão Escolar e Tecnologias. 2009. Disponível em: $<$ http://www.eadconsultoria.com.br/matapoio/biblioteca/textos_pdf/ texto18.pdf>. Acesso em: 24 maio 2012.

SANTOS, C. G. dos. Webquest no ensino e aprendizagem do inglês. 2012. Dissertação (Mestrado em Letras) - Universidade Católica de Pelotas, 2012.

SCHLATTER, M; GARCEZ, P. M. Línguas Adicionais (Espanhol e Inglês). In: RIO GRANDE DO SUL, Secretaria de Estado da Educação, Departamento Pedagógico. (Org.). Referencias curriculares do Estado do Rio Grande do Sul: linguagem, códigos e suas tecnologias. Porto Alegre: Secretaria de Estado da Educação, Departamento Pedagógico, 2009. v. 1, p.127-172.

SCHLATTER, M; GARCEZ, P. M. Linguas Adicionais na escola: aprendizagens colaborativas em inglês. Erechim: Edelbra, 2012.

SCHÖN, D. A. Formar Professores como Profissionais Reflexivos. In: NÓVOA, A. (Org.). Os professores e a sua formação. Lisboa: Publicações Don Quixote, 1995. THIOLLENT, M. Metodologia da pesquisa-ação. 14. ed. São Paulo: Cortez Editora, 2005.

TITONE, R. Teaching foreign languages: an historical sketch. Washington: Georgetown University Press, 1968.

TRIP, D. Pesquisa-ação: uma introdução metodológica. Educação e Pesquisa, v. 31, n. 3, p. 443-466, 2005.

VETROMILLE-CASTRO, R. A interação social e o beneficio reciproco como elementos constituintes de um sistema complexo em ambientes virtuais de aprendizagem para professores de línguas. 2007. Tese (Doutorado) - Programa de Pós-Graduação em Informática na Educação, Universidade do Rio Grande do Sul, Porto Alegre, 2007. 
VOLTAIRE. Candide: ou, L'optimisme; édition critique avec une introd. et un commentaire par André Morize. [S.l.: s.n.], 1931.

WIDDOWSON, H.G. Teaching language as communication. Oxford: Oxford University Press, 1978.

YONEKURA, H. Foreign language teaching methods: a historical sketch. Bull. Nara Univ. Educ., v. 3, n. 1, p. 19-30, 1984. 